IgG and IgM antibodies to KLH over time. A dose-response model was generated for TDAR inhibition. Blood samples were collected to evaluate PK, total soluble CD40L (sCD40L) and ADA concentrations.

Results: No deaths, TEs, severe or serious hypersensitivity reactions or infections or infusion-related reactions were observed in the study. One serious adverse event (fractured tibia) was reported in the placebo arm. MEDI4920 showed inhibition of the TDAR IgG response after the second administration of KLH on Day 15 at higher doses ( $\geq 300 \mathrm{mg}$; Figure $1 \mathrm{~A}$ ). An $E_{\max }$ model adequately characterised the TDAR dose-response at Day $43\left(p<0.001 ; E_{50}=491 \mathrm{mg}\right)$, with the $3000 \mathrm{mg}$ dose showing $86 \%$ inhibition of the TDAR $(95 \% \mathrm{Cl}: 68-94 \%$; Figure 1B). MEDI4920 exhibited linear PK. MEDI4920 produced a dose-dependent increase in total SCD40L concentrations. A high ADA incidence $(90 \%)$ was observed in dose cohorts $\leq 100 \mathrm{mg}$; however, ADA incidence (29\%) and ADA titres decreased with $\geq 300 \mathrm{mg}$ doses of MEDI4920. ADA-high subjects had reduced MEDI4920 and total SCD40L concentrations compared with ADAnegative subjects or those with low ADA titres. ADA incidence did not correlate with any clinical events.

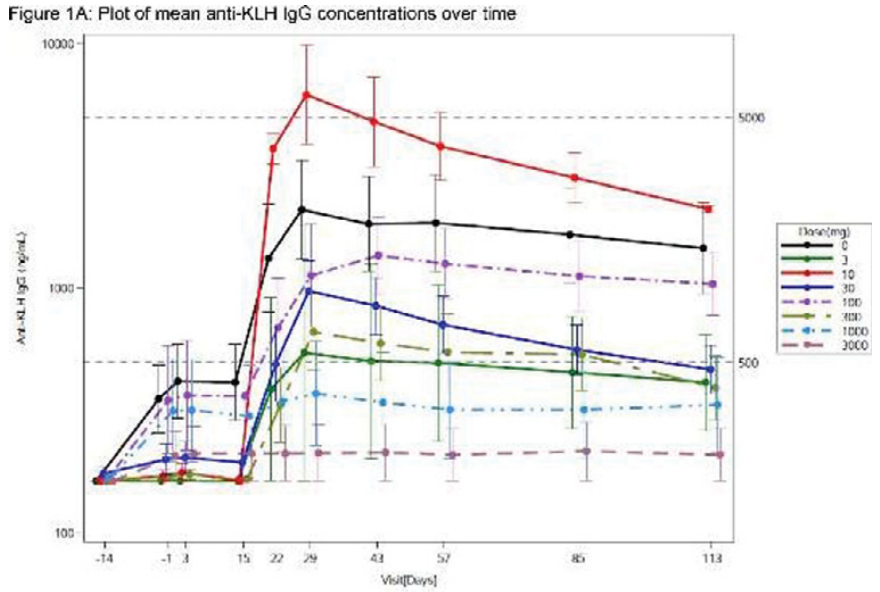

Figure 1D: Plot of dose-response model for TDAR inhibition (anti-KLI I lgG at Day 43)

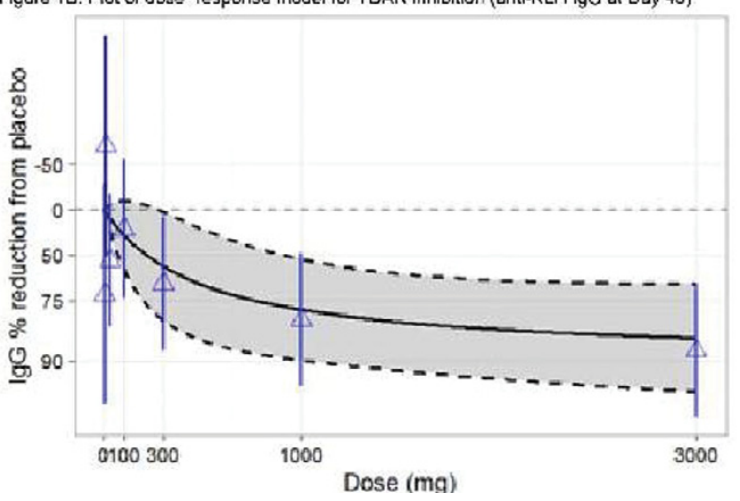

Conclusions: MEDI4920 demonstrated an acceptable safety and tolerability profile, and dose-dependent inhibition of TDAR. The dose-dependent increase in total SCD40L concentrations indicates binding of MEDI4920 to SCD40L and target engagement. The decreases in ADA incidence and ADA titres correlate with increasing MEDI4920 dose, consistent with the immunosuppressive mechanism of action of this molecule. These results support further exploration of MEDI4920 administration in subjects with autoimmune diseases where the CD40/CD40L pathway is activated.

Acknowledgements: Funded by Medlmmune. Medical writing support: D. Trivedi, Medlmmune LLC, Gaithersburg, MD, USA. Technical editing support: R. Plant, QXV Comms, an Ashfield company, which was funded by Medlmmune.

Disclosure of Interest: M. Albulescu Shareholder of: Medlmmune, Employee of: Medlmmune, M. Gunsior Employee of: Medlmmune, J. Li Employee of: Medlmmune, J. Bush Employee of: Covance Clinical Research Unit Ltd (Co. contracted [and paid] by the sponsor to conduct the study), A. Godwood Shareholder of: AstraZeneca, Employee of: Medlmmune, R. Miday Employee of: Medlmmune, E. Grant Shareholder of: AstraZeneca, Employee of: Medlmmune, D. Howe Employee of: Medlmmune, R. Faggioni Shareholder of: AstraZeneca, Employee of: Medlmmune, L. Roskos Shareholder of: AstraZeneca, Employee of: AstraZeneca

DOI: 10.1136/annrheumdis-2017-eular.3468

\section{SAT0250 BODY MASS INDEX IS INVERSELY ASSOCIATED WITH RESPONSE TO RITUXIMAB IN LUPUS NEPHRITIS: ANALYSIS OF THE LUNAR TRIAL}

M.D. Cascino ${ }^{1,2}$, L.M. Gomez Mendez ${ }^{1}$, J. Garg ${ }^{2}$, L. Dragone ${ }^{2}$, M. Dall'Era ${ }^{1}$, P. Brunetta ${ }^{2}{ }^{1}$ University of California - San Francisco, San Francisco;

${ }^{2}$ Genentech, Inc., South San Francisco, United States

Background: Increased body mass index (BMI) has been associated with poor functional capacity and systemic inflammation in lupus, ${ }^{1}$ alterations in rituximab (RTX) pharmacokinetics, ${ }^{2}$ and failure to achieve trial endpoints among patients treated with RTX for ANCA-associated vasculitis. ${ }^{3}$ Although RTX is not approved for the treatment of lupus nephritis (LN), current EULAR/ERA-EDTA guidelines include RTX for use in refractory cases. ${ }^{4}$ The effect of BMI on outcomes of patients treated with RTX for LN is unknown.

Objectives: To assess the association between pre-treatment BMI and renal response using data from the LUNAR trial.

Methods: LUNAR randomized 144 patients with ISN/RPS class III or IV LN to RTX (2 doses of $1000 \mathrm{mg}$ at baseline and month 6 ) or placebo in combination with mycophenolate and a steroid taper. ${ }^{5}$ BMI was measured at the screening visit. Complete renal response (CRR) was defined as achievement of UPCR $<0.5$, normal serum creatinine not increased from baseline by $>15 \%$, and inactive urinary sediment at week 52 . Alternative definitions of response and achievement of CRR at week 78 were also considered. Logistic regression was used to model interactions and to calculate odds ratios $(\mathrm{OR})$ and $95 \% \mathrm{Cl}$. Peripheral CD19+ $\mathrm{B}$ cell measurements were examined.

Results: We identified qualitative interactions between BMl and treatment for CRR and alternative response measures. In unadjusted analysis, each $5 \mathrm{~kg} / \mathrm{m}^{2}$ increase in pre-treatment BMI was associated with OR $=0.47$ (95\% Cl 0.24-0.92) in the RTX group and $\mathrm{OR}=1.44(95 \% \mathrm{Cl} 0.93-2.23)$ in the placebo group for achievement of CRR ( $P$ value for interaction $=0.006)$. The results of analysis adjusted for baseline UPCR and serum creatinine are presented in the Table. A sensitivity analysis identified consistent associations between BMI and response in the RTX group only. Among patients in the RTX group, increased BMI was associated with increased time to peripheral CD19+ ${ }^{+}$count $<5$ cells $/ \mu \mathrm{L}$ (Figure).

Table 1

\begin{tabular}{lllc}
\hline & \multicolumn{2}{c}{$\begin{array}{c}\text { Adjusted OR }(95 \% \mathrm{Cl}) \text { per } 5 \mathrm{~kg} / \mathrm{m}^{2} \\
\text { increase in pre-treatment } \mathrm{BMI}\end{array}$} & $P$ value for interaction \\
\cline { 2 - 3 } Response measure & Rituximab $(\mathrm{n}=72)$ & Placebo $(\mathrm{n}=72)$ & \\
\hline CRR & $0.48^{\star}(0.23-0.97)$ & $1.60^{\star}(1.01-2.55)$ & 0.005 \\
Overall renal response & $0.78(0.51-1.19)$ & $1.42(0.94-2.16)$ & 0.045 \\
UPCR $<0.5$ & $0.61^{\star}(0.38-0.97)$ & $1.37(0.91-2.07)$ & 0.010 \\
UPCR $<0.7$ & $0.58^{\star}(0.37-0.92)$ & $1.33(0.87-2.02)$ & 0.010 \\
CRR at week 78 & $0.53^{\star}(0.29-0.99)$ & $1.58(0.99-2.52)$ & 0.006 \\
\hline
\end{tabular}

${ }^{*} P<0.05$.

All endpoints were measured at week 52 except where specified.

Figure. Kaplan-Meier estimates: Time to peripheral CD19+ count $<5$ cells $/ \mu \mathrm{L}$

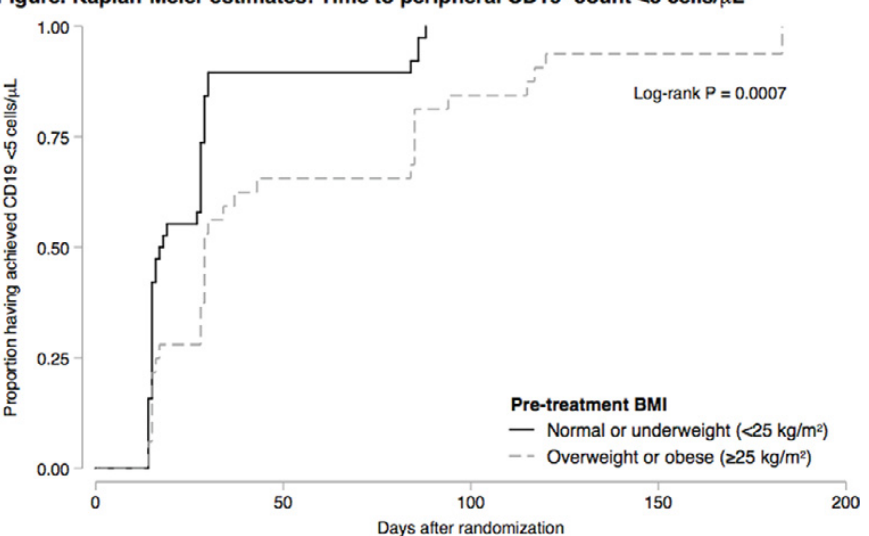

Conclusions: In this exploratory analysis of the LUNAR trial, BMI was inversely associated with renal response among patients treated with RTX. We did not observe this same relationship between $\mathrm{BMI}$ and response among patients in the placebo group, and in fact found evidence of a positive correlation between BMI and one measure of response in this group. Among patients treated with RTX, BMI was associated with time to $B$ cell depletion, generating the hypothesis that the observed differences in response are mediated by differences in the timing and/or degree of $\mathrm{B}$ cell depletion. These findings warrant additional analyses to better understand the relationships between patient characteristics, pharmacokinetics, $\mathrm{B}$ cell depletion, and treatment response in the LN population.

References:

[1] Oeser Arthritis Rheumatol 2005

[2] Müller Blood 2012

[3] Bertsias Ann Rheum Dis 2012.

[4] Rovin Arthritis Rheumatol 2012.

LUNAR trial NCT00282347. 
Disclosure of Interest: M. Cascino Employee of: Roche/Genentech, L. Gomez Mendez Grant/research support from: Roche/Genentech, J. Garg Employee of: Roche/Genentech, L. Dragone Employee of: Roche/Genentech, M. Dall'Era: None declared, P. Brunetta Employee of: Roche/Genentech DOI: 10.1136/annrheumdis-2017-eular.5535

\section{SAT0251 PREDICTING AND MANAGING PRIMARY AND SECONDARY NON-RESPONSE TO RITUXIMAB USING B-CELL BIOMARKERS IN SYSTEMIC LUPUS ERYTHEMATOSUS}

M.Y. Md Yusof ${ }^{1,2}$, D. Shaw ${ }^{1}$, Y.M. El-Sherbiny ${ }^{1,2}$, A.C. Rawstron ${ }^{3}$, P. Emery ${ }^{1,2}$, E.M. Vital ${ }^{1,2} .{ }^{1}$ Rheumatology, Leeds Institute of Rheumatic and Musculoskeletal Medicine, University of Leeds; ${ }^{2}$ NIHR Leeds Musculoskeletal Biomedical

Research Unit; ${ }^{3}$ Haematological Malignancy Diagnostic Service, Leeds Teaching Hospitals NHS Trust, Leeds, United Kingdom

Background: Rituximab (RTX) is the most commonly used biologic for the treatment of SLE. However, there is are no clinically applicable predictors of response, which is of particular importance in this heterogeneous disease with other biologics being restricted to certain subgroups.

Objectives: To assess factors associated with primary and secondary nonresponse to RTX in SLE in order to develop more targeted and effective B-cell therapy.

Methods: A prospective observational study was conducted in 125 SLE patients treated with RTX in Leeds for over 12 years. A major clinical response was defined as improvement of all active BILAG-2004 domains to grade C/better and no $A / B$ flare. Partial responders were defined by 1 persistent BILAG B. B-cell subsets were measured using highly sensitive flow cytometry. Predictors of response were analysed using logistic regression analysis.

Results: 117 patients had evaluable data. In cycle 1 (C1), 96/117 (82\%) achieved BILAG response [major $=50 \%$,partial $=32 \%$ ]. In MVA, younger age \& B-cell depletion at 6 weeks increased the odds of major response (Table 1). Complete depletion was predicted by normal complement \& lower pre-RTX plasmablasts. 77 (with data on 72) C1 responders were retreated on clinical relapse. Of these, $61 / 72(85 \%)$ responded in C2. Of $11 \mathrm{C} 2$ non-responders, 9 met secondary non-depletion non response (2NDNR) criteria, as defined by infusion reaction \& defective depletion (incidence $=12 \%$ ) and tested positive for anti-RTX antibodies. Lack of concomitant immunosuppressant \& higher pre-RTX plasmablasts predicted 2NDNR.

Conclusions: B-cell subsets should be monitored in the routine care of SLE patients receiving RTX and should aim to achieve complete depletion. About 1 in 8 SLE patients lose depletion on repeat cycles and this is associated with anti-RTX antibodies. Clinical trials using more intensive RTX treatment regimens in those predicted not to completely deplete, or alternatively use of humanised anti-CD20mAbs are likely to increase clinical response rates to B-cell depleting agents.

Acknowledgements: This research was funded/supported by NIHR (DRF-201407-155) and (CS-2013-13-032). The views expressed are those of the author(s) \& not necessarily those of the NHS, NIHR or the Dept of Health

Disclosure of Interest: None declared

DOI: 10.1136/annrheumdis-2017-eular.6943

\section{SAT0252 THE NUMBER OF TREG CELLS IN PERIPHERAL BLOOD IN PSS PATIENTS IS DECREASED AND LOW DOSE IL-2 CAN PROMOTE ITS PROLIFERATION}

M. Miao ${ }^{1}$, Z. Hao ${ }^{1}$, Y. Guo ${ }^{1}$, X. Zhang ${ }^{2}$, S. Zhang ${ }^{1}$, X. Wu ${ }^{2}$, D. Xu ${ }^{1}$, C. Gao ${ }^{3}$, X. Li ${ }^{2}{ }^{1}$ The Second Hospital of Shanxi Medical University; ${ }^{2}$ Department of Rheumatology, the Second Hospital of Shanxi Medical University, Taiyuan, China; ${ }^{3}$ Department of Pathology, Joint Program in Transfusion Medicine, Brigham and Women's Hospital/Children's Hospital Boston, Boston, United States

Background: PSS is a kind of autoimmune disease without clear pathogenesis. Treg cell plays an important role in autoimmune disease. However, opinions about change of amount of Treg cells in peripheral blood in autoimmune disease are various. Besides, the researches mainly focus on RA and SLE but not PSS.

Objectives: To explore the change of the number of Th17 and Treg (CD4+CD25+Foxp3+T cells) cells in peripheral blood in PSS and the effects of low dose IL-2 therapy on the balance of Treg and Th17 cells.

Methods: One hundred and ninety two PSS patients in our department, and 30 healthy controls were put in the research. The amount of Th17 cells and Treg cells were calculated by flow cytometry. Eighty eight in 192 were given low-dose IL-2 (50 WIU/day for 5 days) by hypodermic injection combined with standard therapy which includes glucocorticoid, immune-suppressants, biological agents or combination of them, while others (12 in 69) were given standard therapy only. The amount of these cells were calculated again after therapy.

Results: There was significant decrease in the absolute number of Treg cells and significant increase of the ratio of Th17/Treg cells in PSS patients when compared with healthy controls. There was no significant difference in absolute number of Th17 cells between PSS patients and healthy controls. Further, the number of Treg cells were negatively relative to ESSDAI. Traditional DMARDs had no obvious impact on Treg and Th17 cells. The amount of Treg cells significantly increased after the treatment of IL-2 by 1 week. But there was no significant improvement in clinical manifestations in the short time when comparing combinational treatment of IL-2 and classical drugs with classical therapy. No obvious adverse reactions were observed.

Table 1. Absolute number and percentage of CD4+T subsets in peripheral blood in PSS patients and Healthy controls.

\begin{tabular}{lccc}
\hline Study Participants & Health & PSS & Untreated PSS \\
\hline Th17 & $6.44(5.10,8.55)$ & $7.09(4.05,11.48)$ & $6.08(4.30,12.60)$ \\
Treg & $36.20(27.82,47.02)$ & $28.24(15.89,41.36)^{\star}$ & $27.30(17.43,39.87)^{\star}$ \\
Th17\% & $0.96(0.67,1.33)$ & $1.26(0.77,1.95)^{\star}$ & $1.26(0.86,1.92)^{\wedge}$ \\
Treg\% & $4.80(4.19,6.37)$ & $4.64(3.10,6.44)$ & $4.70(2.52,6.91)$ \\
Th17/Treg & $0.18(0.14,0.29)$ & $0.27(0.15,0.43)^{\star}$ & $0.28(0.15,0.47)^{\wedge}$ \\
\hline
\end{tabular}

Median (range, cells $/ \mu \mathrm{l}) .{ }^{\wedge} \mathrm{P}<0.1,{ }^{*} \mathrm{p}<0.05,{ }^{\star \star} \mathrm{p}<0.01,{ }^{\star \star \star} \mathrm{p}<0.0001$ vs Healthy controls.

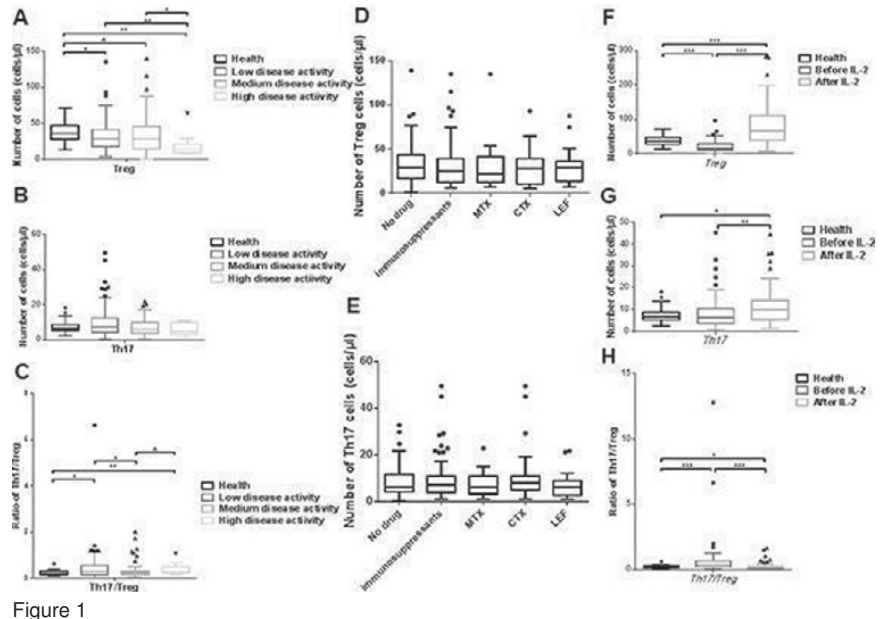

Conclusions: The number of CD4+CD25+Foxp3+T cells in peripheral blood was decreased obviously and was inversely related to ESSDAI. While there was no significant difference of Th17 cells between PSS patients and healthy controls. And there was no correlation between the number of Th17 cells and ESSDAI. So the imbalance of Th17/Treg is due to the decrease of Treg cells not increase of Th17 cell which indicates that the pathogenesis of PSS maybe mainly because of shortage of autoimmune tolerance. Low dose IL-2 therapy can effectively promote proliferation of Treg cells by which low dose IL-2 may induce and restore autoimmune tolerance to benefit disease control.

References:

[1] Takayoshi Morita et al. The Proportion of Regulatory T Cells in Patients with Rheumatoid Arthritis: A Meta-Analysis. PLoS One. 2016 Sep 13.

[2] Noack, M. \& Miossec, P. Th17 and regulatory T cell balance in autoimmune and inflammatory diseases. Autoimmun Rev. 13, 668-677 (2014).

Disclosure of Interest: None declared

DOI: 10.1136/annrheumdis-2017-eular.6366

Abstract SAT0251 - Table 1

\begin{tabular}{|c|c|c|c|c|}
\hline & Non/Partial Response $(n=59)$ & Major Clinical Response $(n=58)$ & UVA OR $(95 \% \mathrm{Cl})$, P-value & MVA OR $(95 \% \mathrm{Cl})$, P-value \\
\hline Age, mean (SD) years & $43(17)$ & $37(14)$ & $0.97(0.95-0.99), p=0.031$ per year & $0.97(0.94-0.99), p=0.037$ \\
\hline White, N (\%) & $43(73)$ & $37(64)$ & $1.53(0.70-3.34), p=0.292$ & $0.93(0.34-2.54), p=0.882$ \\
\hline Anti-dsDNA, mean (SD) IU/ml & $147(230)$ & $142(230)$ & $1.00(0.99-1.00), p=0.913$ per unit & $1.00(0.99-1.00), p=0.518$ \\
\hline Anti-ENA positivity, N (\%) & $40(68)$ & $38(66)$ & $0.93(0.42-2.06), p=0.860$ & $1.00(0.39-2.57), p=1.00$ \\
\hline Low C3 and/or C4, N (\%) & $25(42)$ & $24(41)$ & $0.97(0.46-2.06), p=0.945$ & $1.33(0.46-3.80), p=0.599$ \\
\hline ESR, mean (SD) mm & $40(32)$ & $41(36)$ & $1.00,(0.99-1.01), p=0.901$ per unit & $1.00(0.97-1.00), p=0.349$ \\
\hline Concomitant DMARDs, N (\%) & $41(69)$ & $35(60)$ & $0.67(0.31-1.43), p=0.301$ & $0.39(0.16-1.00), p=0.051$ \\
\hline Global BILAG, mean (IQR) & $21(8)$ & $24(13)$ & $1.03(0.99-1.07), p=0.093$ per point & $1.03(0.98-1.08), p=0.191$ \\
\hline Total B-cell counts $\times 1000$ mean (IQR) & $101(95)$ & $138(150)$ & $1.00(1.00-1.01), p=0.169$ per unit & $1.00(1.00-1.01), p=0.103$ \\
\hline B-cell depletion at 6 weeks, $\mathrm{N}(\%)$ & $29(49)$ & $39(68)$ & $2.15(0.98-4.71), p=0.056$ & $3.44(1.25-9.48), p=0.017$ \\
\hline
\end{tabular}

